American Journal of Pharmaceutical Education 2019; 83 (8) Article 7627.

\title{
COMMENTARY
}

\section{Pharmacy in an Improved Health Care Delivery Model Using Maslow's Hierarchy of Needs}

\author{
Therese I. Poirier, PharmD, MPH ${ }^{\mathrm{a}, \mathrm{b}}$ Radhika Devraj, PhD \\ ${ }^{a}$ Southern Illinois University Edwardsville, Edwardsville, Illinois \\ ${ }^{\mathrm{b}}$ Editorial Board Member, American Journal of Pharmaceutical Education, Arlington, Virginia
}

Submitted April 15, 2019; accepted May 14, 2019; published October 2019.

\begin{abstract}
Our objective is to suggest a revised model of health care delivery that emphasizes human connections in patient care and describes the role of pharmacists within the model. Improving the quality of patient experiences is one of the triple aims of health care delivery. Using the patient-centered medical home (PCMH) model as the basis, we describe an enhanced delivery model that adopts Maslow's hierarchy of needs and addresses the current deficiencies of the PCMH model. The model envisions the creation of "community centers for engagement" that employ patient care advocates and health care practitioners who work together in an interdisciplinary manner to improve the quality of patient care experiences. Pharmacists' roles in these centers of engagement are outlined based on Maslow's hierarchy of needs. The model aims to enhance patient-provider interactions and allow pharmacists to play a pivotal role in meeting patients' needs with the goal of developing a self-actualized patient.
\end{abstract}

Keywords: pharmacist roles, health care delivery, Maslow's hierarchy of needs

Health care delivery in the United States is primed for dramatic changes due to recent trends in the health care environment. These trends include increasing self-care movement, growth in complementary and alternative therapies, greater use of social media and technology, and more recently, the use of artificial intelligence, the use of grocery shopping and home deliveries including drone deliveries, and the online marketplace with Amazon's recent foray into the health care market. ${ }^{1-4}$ All of these trends have implications that affect the quality of patient experiences with health care providers. Providing optimal health care requires attention to the triple aims of health care delivery. ${ }^{5}$ Enhancing the patient experience is one of those aims. ${ }^{5}$ While the remaining two aims of health care delivery (reducing health care costs and improving population health) have received significant attention, not much consideration has been directed toward improving the patient care experience. Improving the experience with patient care delivery could be influenced by enhancing the provider-patient interaction. Researchers have previously implied that the current model of health care delivery does not adequately address the quality of patient experiences. ${ }^{6}$ A model of health care delivery that emphasizes human connection is needed. A report by Rupp suggests that many elderly believe they have needs that cannot be met by mail service

Corresponding Author: Therese I. Poirier, Southern Illinois University Edwardsville, 200 University Park, Edwardsville, IL 62026. Tel: 618-650-5155. E-mail: tpoirie@siue.edu. and are opposed to mandatory mail service if this implied that the community pharmacy would close; thereby reaffirming patients' preferences for human interactions. ${ }^{2}$

The need to enhance the human connection within health care has implications for how we practice pharmacy and may suggest areas for changes in pharmacy education. Recent models of health care delivery such as the patientcentered medical home (PCMH) can serve as a foundation for any enhancements in the model. Elements of PCMH that are key to enhancing clinical quality are care continuity, access, care coordination, teamwork and communication. ${ }^{7}$ However, there are shortcomings of the PCMH model which include inadequate links between the community and medical care and lack of training on self-management. ${ }^{8}$ Mielenz further advocated for a person-centered wellness home $(\mathrm{PCWH})$ framework that uses community resources to set goals tailored to patients' needs. ${ }^{8}$ He referred to the use of community health workers who would serve as lay leaders or coaches to provide relationship-centered care in the community. Fiscella recently commented that the PCMH needs to be re-designed and built on a foundation of human needs and enhanced partnerships with community service organizations. ${ }^{9}$ Flieger commented that the current PCMH model is more focused on the structure than on the relationship aspect. ${ }^{10}$ The need for enhanced communication, empathy and collaboration are areas for PCMH improvements.

While the existing traditional biomedical model of health care delivery focuses mainly on addressing 


\section{American Journal of Pharmaceutical Education 2019; 83 (8) Article 7627.}

physiological needs, an enhanced holistic model based on Maslow's hierarchy is needed to improve care delivery in today's health care environment. Dawlatly commented that the current model of care does not address Maslow's needs of love and belonging. ${ }^{11}$ We suggest using the PCMH as a foundation and incorporating Maslow's hierarchy of needs framework with attention to socio-psychological needs. This would address deficiencies in the PCMH model and would create an enhanced model of health care delivery that can address patients' unmet needs associated with human interaction.

The first step for designing an enhanced health care delivery model requires an understanding of the hierarchy of patients' health care needs. Maslow's theory of the hierarchy of needs, originally designed as a motivational theory, can serve as the basis for the revised health care delivery model. ${ }^{12}$ Maslow proposed five hierarchies of needs represented in a pyramid: physiological needs, safety needs, love and belonging needs, self-esteem needs, and self-actualization. Conceptually, Maslow's framework has been used previously to describe meeting the needs for Type I diabetes, palliative care and hospice patients. $^{13,14}$

To achieve this goal, we suggest the development of "community centers of engagement." These centers of engagement can be either physical or virtual centers connected via health information technology with the goal of enhancing human connections and providing holistic experiences. Extensive efforts in providing education to enhance motivation for individuals to become health conscious would be a major focus of these centers. These centers could employ patient care advocates (PCA), who would perform an initial screen to determine specific health care needs required for each patient followed by coordinating their care with other providers as necessary, with the goal of ensuring enhanced human connections between individuals and primary care providers (PCPs). These advocates would be expected to provide a variety of services such as wellness information, physical fitness, nutritional needs, self-management help, medication management resources and tips, and access to other health-based community resources. Ideally, PCAs would be individuals with limited health training but have enhanced training for developing skills such as empathy, patient-centered attitudes, communication, self-awareness, and relatability to others. Undergraduate health humanities programs could be structured to satisfy the training needs of these types of health care workers. Thus, these centers can serve not only to enhance the human connection of health care but also to ensure coordination of care with the PCP in addition to providing quality clinical care. ${ }^{15}$
PCPs as part of their care planning could refer patients to these centers. PCPs could be either primary care physicians, or mid-level providers such as nurse practitioners or physician assistants. The PCP would always not need to be physically present at the centers, as video conferencing technology could be used for communication with patients. The responsibilities of the PCP would be similar to the existing models of care delivery and include responsibilities to diagnose, provide evidence-based care planning and monitoring and recommend the need for specialist consultants. We anticipate that health insurance plans would reimburse for services provided at the centers in the revised health care delivery model because it focuses on providing comprehensive holistic care and may reduce their overall costs in the long term. The improved health care delivery model would retain features of the current managed care system where all patients would have a PCP working closely with a PCA employed at the centers.

Pharmacists could play a pivotal role in these centers for engagement. They could serve as a new mid-level provider with a defined scope of practice when credentialed as a qualified provider or serve as specialist consultants for complicated pharmacotherapeutic challenges. Additionally, pharmacists can concentrate their efforts on teaching patients self-management skills, tailor their regimens to enhance adherence and use their motivational interviewing skills to educate patients in an empathetic manner about the significance of medication adherence. Even if pharmacists do not become primary care providers, active involvement of the "patient care literate" pharmacist (a pharmacist trained with enhanced interpersonal skills ) in a revised integrative PCMH model would improve care quality and help address Maslow's hierarchy of needs. ${ }^{16-20}$ The use of health information technology could aid pharmacists in their efforts as they develop skills and abilities of patients. Thus, pharmacists working with centers of engagement could meet the various hierarchies of patients' needs, eventually developing them to become self-actualized and health literate.

Figure 1 depicts the roles for pharmacists in this enhanced model of health care delivery based on Maslow's hierarchy of needs. Physiological needs are currently met by advances in medication distribution systems and use of technology. Safety needs will be enhanced when a PCMH uses integrated electronic medical records to promote communication and sharing of information. Pharmacists' enhanced self-awareness, empathy, and patient care literacy centered attitudes could help address patients' call for a health care provider who will listen and be concerned with them as a person. Pharmacists can help meet self-esteem needs by enhanced 


\section{American Journal of Pharmaceutical Education 2019; 83 (8) Article 7627.}

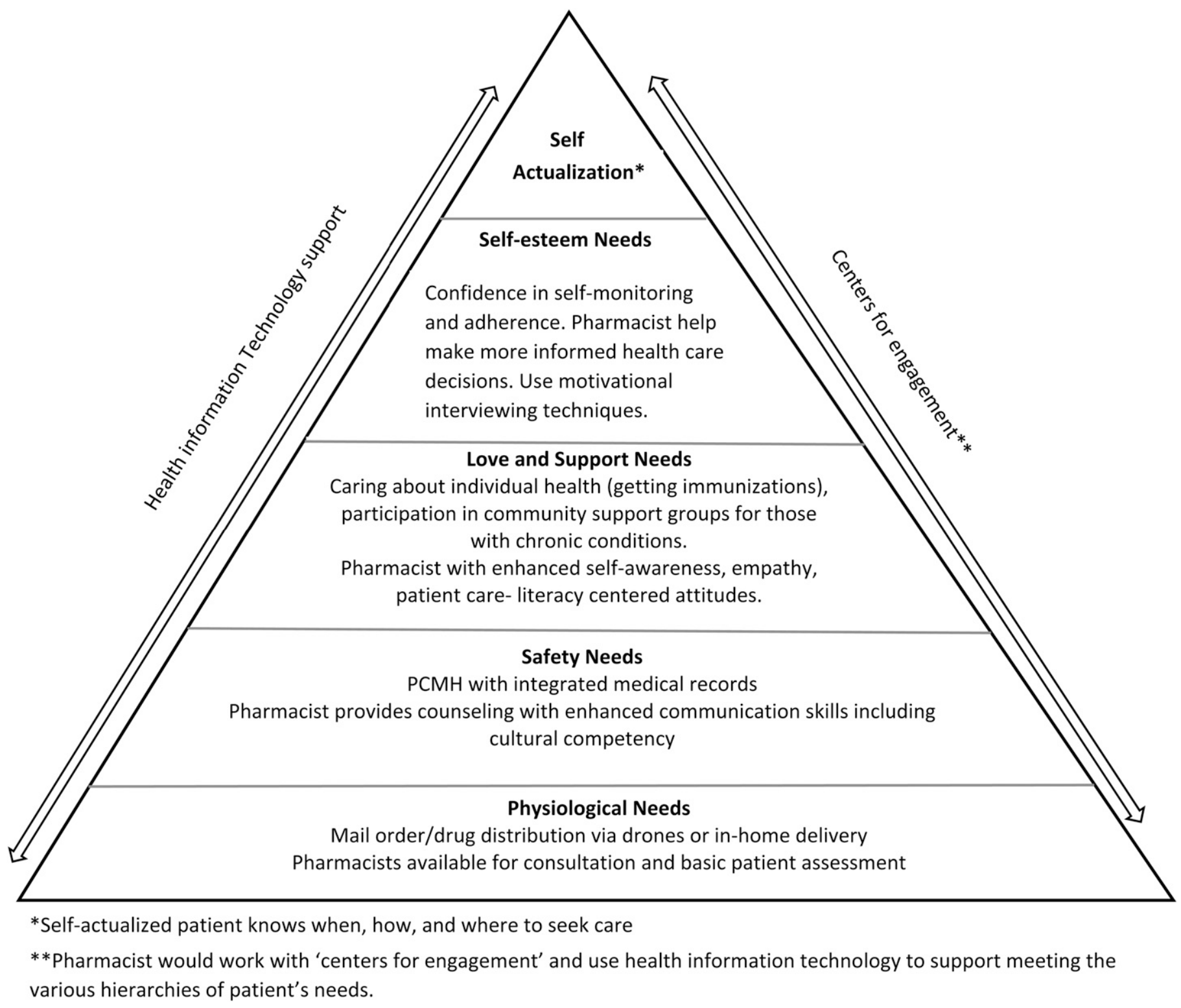

Figure 1. Pharmacist Roles for Enhancing Patient Experiences Using Maslow's Hierarchy of Needs in Revised Model of Health Care Delivery

involvement in providing individualized education and developing patients' confidence in self-monitoring and adherence, so patients become informed and active health care participants. Training in techniques such as motivational interviewing will help develop pharmacist roles in this area. The need for self-actualization where patients become more independent about advocating and seeking their own care needs is the ultimate goal.

We are hopeful that enhanced integration and communication with community partners including pharmacies would help optimize quality of care and improve utilization of preventive services, decrease costs, improve access, and enhance patient satisfaction while meeting the individual's hierarchy of needs. Specific types of patients such as the elderly and those with chronic diseases may be more likely to benefit. However, with a focus on health and wellness even young and healthy people could benefit.

Achieving this model will require changes across multiple fronts. Enhancing the role of pharmacy in an improved health care delivery model aimed at enhancing human connections and meeting patients' hierarchy of needs will not only require changes in reimbursement models but also further pharmacy education reform. ${ }^{20}$ An enhanced understanding of patients' personal and emotional needs is necessary.

Additionally, current curricular efforts in developing interprofessional practice skills and behaviors would be 


\section{American Journal of Pharmaceutical Education 2019; 83 (8) Article 7627.}

valuable competencies for pharmacists practicing in the new centers for engagement.

Advances in technology for drug distribution coupled with educational reforms would allow pharmacists to assume an increased role in meeting the different hierarchies of patients' needs. Educational reforms, which emphasize interprofessional collaboration, enhanced communication skills, human connection in patient experiences, which develops both patient-centered attitudes and the use of health information technology should be accelerated in existing curricula. These changes would assist in expanding pharmacists' roles in this revised health care delivery model.

\section{REFERENCES}

1. Zhu P, Hilsenrath P. Mergers and acquisitions in US retail pharmacy. J Health Care Finance. 2014:41(3):1-20.

2. Rupp M. Attitudes of Medicare-eligible Americans toward mail service pharmacy. J Manag Care Pharm. 2013;19(7):564-572.

3. Ferguson T. Self-care: the growing trend toward selfresponsibility for health. http://www.healthy.net/Health/Article/ The_Growing_Trend_Toward_Self_Responsibility_ for_Health_Part_I/1013. Accessed March 19, 2019.

4. Lin C, Shah K, Mauntel C, Shah S. Drone delivery of medications: review of the landscape and legal considerations. Am J Health-Syst Pharm. 2018;75(3):153-158.

5. Berwick DM, Nolan TW, Whittington J. The triple aim: care, health and cost. Health Affairs. 2008;27(3):759-769.

6. Agency for Health Care Research and Quality. https:// www.ahrq.gov/cahps/about-cahps/patient-experience/index.html. Accessed March 18, 2019.

7. Khanna N, Shaya F, Gaitonde P, et al. Evaluation of PCMH model adoption on teamwork and impact on patient access and safety. $J$

Primary Care Com Health. 2017;8(2)77-82.
8. Mielenz T, Allegrante J, Rowe J. Patient-centered medical home, make room for your new neighbor. Med Care. 2016;54(8):735-737. 9. Fiscella K. Commentary on 'Rebuild the patient-centered medical home on a foundation of human needs.' J Amb Care Manage. 2017;40(2):101-106.

10. Flieger SP. Implementing the patient-centered medical home in complex adaptive systems: becoming a relationship-centered patientcentered medical home. Health Care Manage Rev. 2017;42(2)112121.

11. Dawlatly S. Do our consultation models meet our patients' needs? Br J Gen Pract. 2014;64(622):245.

12. Cherry K. The five levels of Maslow's hierarchy of needs. https:// www.verywell.com/what-is-maslows-hierarchy-of-needs-4136760. Accessed March 18, 2018.

13. Beran D. Developing a hierarchy of needs for type 1 diabetes. Diabetic Medicine. 2014;31:61-67.

14. Zalenski R, Raspa R. Maslow's hierarchy of needs: a framework for achieving human potential in hospice. J Pall Med.

2006;9(5):1120-1127.

15. Kleber-Emmons A, Miller W. The patient-centered medical home $(\mathrm{PCMH})$ framing typology for understanding the structure, function, and outcomes of PCMHs. J Am Board Fam Med. 2017;30:472-479.

16. Dobbins M, Thomas S, Melton S, Lee S. Integrated care and the evolution of the multidisciplinary team. Prim Care Clin Office Pract. 2016;43:177-190.

17. Gorbenko K, Fraze T, Lewis V. Redesigning care delivery with patient support personnel: learning from accountable care organizations. Inter J Care Coord. 2016;19(3-4):73-83.

18. Amara S, Adamson R, Lew I, Slonim A. Accountable care organizations: impact on pharmacy. Hosp Pharm. 2014;49(3)253259.

19. Adams A, Clark D, DeLander G, et al. Opportunities and responsibilities for the academy in the medical home. Am J Pharm Educ. 2013;77(7):Article 137.

20. Poirier TI. Advocating for patient care literacy. Am J Pharm Educ. 2018;81(1):Article 6884. 